\title{
Emerging evidence for gene mutations driving both brain and gut dysfunction in autism spectrum disorder
}

\author{
Beate Niesler (iD) ${ }^{1,2} \cdot$ Gudrun A. Rappold ${ }^{1,2}$
}

Received: 16 November 2019 / Revised: 6 March 2020 / Accepted: 4 May 2020 / Published online: 27 May 2020

(c) The Author(s) 2020. This article is published with open access

Functional gastrointestinal disorders that are common in autism may derive from gene mutations previously linked to behavioral symptoms in autism spectrum disorder (ASD).

There is increasing awareness that patients suffering from neurological disorders including neurodevelopmental and neuropsychiatric diseases often present with gastrointestinal (GI) dysfunction, perceived as pain, stress, or discomfort. To date, the genetic factors associated with neuronal dysfunction in the brain and central nervous systems (CNS) have not been considered relevant in shaping GI symptoms. This has, however, recently changed. GI dysfunction has been described in various neurodevelopmental and psychiatric disorders including autism spectrum disorder and animal models have provided the first insights into how gut function is affected in these disorders [1].

Changes in microbiota composition and the presence of a leaky gut caused by impaired epithelial barrier function have been shown to contribute to changes in CNS structure and function relevant to neurological phenotypes [2, 3]. Within the past decade, evidence has accumulated that suggests microbiota-mediated gut-brain axis impairment also contributes to the pathogenesis of ASD and other disorders [1, 2, 4]. How far the complex pathogenesis is influenced by the host's genetics has been the focus of research groups worldwide.

Here, we wish to highlight the genetic predispositions to ASD using established transcriptional profiles of the brain and gut. Strikingly, more than $90 \%$ of the 62 highest-ranking autism risk genes in the SFARI database

Gudrun A. Rappold

gudrun.rappold@med.uni-heidelberg.de

1 Institute of Human Genetics, Department of Human Molecular Genetics, Heidelberg University, 69120 Heidelberg, Germany

2 Interdisciplinary Center for Neurosciences (IZN), Heidelberg University, 69120 Heidelberg, Germany (https://gene.sfari.org/) are expressed in both brain and GI tissues according to the genotype-tissue GTEx database (https://gtexportal.org/), suggesting they mutually affect the brain and the gut. Moreover, all listed SFARI genes are expressed in murine neural crest cells and enteric neural crest-derived cells that give rise to both peripheral and enteric neurons and glia, and the fetal gut (unpublished data). The expression of so many genes associated with ASD in the GI tract, including the enteric nervous system (ENS) as well as brain regions from embryonic to adult stages, suggests that these proteins might play a fundamental role in the development of the peripheral and CNS.

ASD is a neurodevelopmental disorder with altered behavior as a core feature. Clinically, ASD is characterized by impaired social interaction and communication, limited interests and activities as well as repetitive behaviors, suggesting impaired neuronal function. Moreover, autism severity has been associated with the probability of having GI problems [5].

The pathophysiology of GI dysfunction in ASD is still poorly understood. This may be attributed to the large clinical heterogeneity, multiple underlying genetic causes, environmental factors, and dysbiosis that lead to different developmental manifestations; but awareness of GI complaints in ASD has increased. Assessing GI dysfunction is challenging since symptoms such as pain, discomfort, heartburn, or nausea are difficult to assess and interpret because of difficulties in communication and altered pain perception. Therefore, it is largely unknown whether GI symptoms occur due to GI dysfunction or whether they represent an epiphenomenon caused by altered behavior or side effects of psychotropic medication.

To address this issue, several groups have set up questionnaires for children with ASD and their parents to assess GI symptoms in a standardized way. Studies implementing these systematic evaluations confirmed that feeding problems, functional diarrhea, and constipation as well as gastro-esophageal reflux disease are much more common in children with ASD than in healthy individuals [6]. 


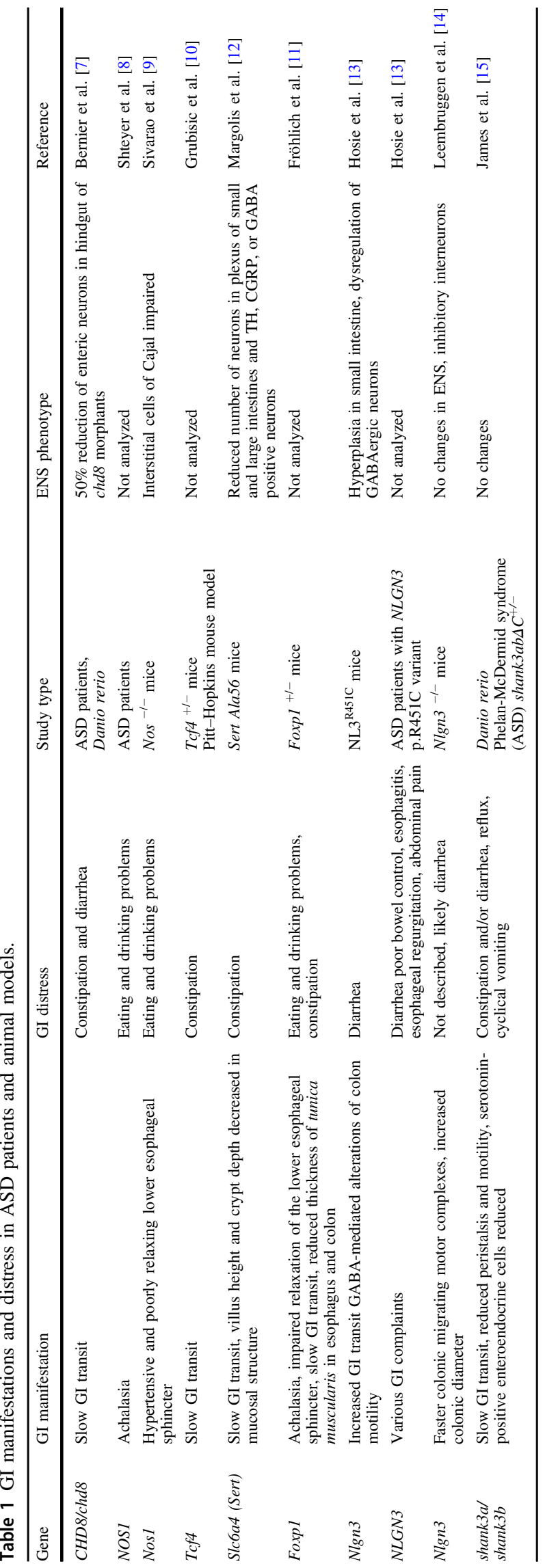

Mutations in several ASD-associated genes have already been reported in patients with upper and lower GI disorders including achalasia and slow-transit constipation. CHD8 mutations, for example, have been reported in patients with ASD that often presented with constipation. This was one of the first examples of an unexpected association between disturbed brain function and altered ENS development [7]. NOS1 mutations were identified in patients diagnosed with autism and achalasia, resulting into eating and drinking problems [8], and FOXP1 mutations were found in patients with ASD symptoms, language impairment, anxiety, and various GI complaints. Pitt-Hopkins syndrome is caused by TCF4 mutations and is characterized by moderate to severe intellectual disability and ASD-associated behavioral deficits; in addition to these symptoms, patients frequently suffer from constipation and gastro-esophageal reflux.

Some studies have now also investigated the GI tract in animal models of ASD. Animal studies previously focused on brain alterations and associated behavioral consequences, while the GI tract has received only limited attention. This has recently changed, and studies are now addressing this issue, thereby underlining the importance of ASD genes in GI phenotypes. Patterns of gut motility in the GI tract of humans are remarkably similar to those of the mouse, meaning findings from these model systems can be extrapolated to human phenotypes [9]. Consistent with the phenotype seen in patients, mice with Tcf4 haploinsufficiency, for example, present with impaired upper GI transit and disturbed rectal motility, leading to constipation [10]. Achalasia and delayed GI transit caused by impaired function of the lower esophageal sphincter and decreased motility, leading to eating and drinking problems and constipation, was observed in Foxp $^{+/-}$mice [11]. Moreover, gain-of-function mutations in the serotonin transporter gene Slc6a4 led to ASD-like behavior and a GI phenotype characterized by ENS hypoplasia and slow GI transit in mice [12]. Recently, mutations in neuroligin-3 (Nlgn3) led to GI dysfunction characterized by colonic dilation and accelerated GI transit, suggesting imbalances in neuronal activity $[13,14]$.

The relevance of ASD genes in GI phenotypes was also corroborated by recent findings of intestinal dysmotility in zebrafish with mutant shank3a and shank3b [15]. Impaired enteric neurogenesis and intestinal motility was reported for Chd8 disruptions in zebrafish, recapitulating the human phenotype of constipation [7]. All these studies are in line with the idea that impairment of CNS-relevant genes might also affect ENS development and impact GI structure and function. These observations also support our hypothesis that impaired GI function, such as achalasia, reflux, and slowtransit constipation are not only comorbidities or epiphenomena but also as much a part of the ASD phenotype as the behavioral symptoms. Therefore, these data indicate that genetic defects affecting CNS structure and function in ASD 
might also affect ENS/GI function, which may explain the high prevalence of GI symptoms seen in ASD.

Abnormal development or disturbed structure and function of the ENS is associated with the development of neuropathic GI motility disorders such as achalasia, pseudoobstruction, or functional constipation [16]. GI motility is orchestrated by a complex regulation and coordinated action of the ENS, smooth muscles cells, and interstitial cells of Cajal (ICCs). Developmental defects caused by gene variants may affect specific cell types or disturb the function of these players, thereby causing variable degrees of abnormal motility that eventually lead to intestinal neuromuscular disorders. Based on the affected cell type, these disorders can be divided into three subtypes: neuropathies (neuronal defects) that seem to hold true for CHD8/chd8, Slc6a4 and Nlgn3 [7, 12, 13, 14], myopathies (smooth muscle cell defects), or mesenchymopathies (ICC defects as seen for Nos1 [8, 9]) (Table 1). However, the development and function of these cells are interconnected, and we need to determine whether a defective cell type is the underlying cause or the consequence of a disorder [16]. To which extent other ASD genes are involved in developmental processes relevant to GI complaints remains to be determined.

In conclusion, clinical GI symptoms in ASD patients may not just be comorbidities or consequences of medications, but have to be considered as part of the phenotype, just like behavioral symptoms. We therefore propose that these indications should be reflected in patient treatment to improve their GI symptoms and prevent serious sequelae. This may also have a positive impact on the overall wellbeing of children and adults with ASD, as GI problems are known to exacerbate existing behavioral abnormalities through increasing pain, stress, or discomfort.

Acknowledgements Open access funding provided by Projekt DEAL.

\section{Compliance with ethical standards}

Conflict of interest The authors declare that they have no conflict of interest.

Publisher's note Springer Nature remains neutral with regard to jurisdictional claims in published maps and institutional affiliations.

Open Access This article is licensed under a Creative Commons Attribution 4.0 International License, which permits use, sharing, adaptation, distribution and reproduction in any medium or format, as long as you give appropriate credit to the original author(s) and the source, provide a link to the Creative Commons license, and indicate if changes were made. The images or other third party material in this article are included in the article's Creative Commons license, unless indicated otherwise in a credit line to the material. If material is not included in the article's Creative Commons license and your intended use is not permitted by statutory regulation or exceeds the permitted use, you will need to obtain permission directly from the copyright holder. To view a copy of this license, visit http://creativecommons.org/licenses/by/4.0/.

\section{References}

1. Rao M, Gershon MD. The bowel and beyond: the enteric nervous system in neurological disorders. Nat Rev Gastroenterol Hepatol. 2016;13:517-28.

2. Cryan JF, O'Riordan KJ, Cowan CSM, Sandhu KV, Bastiaanssen TFS, Boehme M, et al. The microbiota-gut-brain axis. Physiol Rev. 2019;99:1877-2013.

3. Rogers GB, Keating DJ, Young RL, Wong ML, Licinio J, Wesselingh S. From gut dysbiosis to altered brain function and mental illness: mechanisms and pathways. Mol Psychiatry. 2016; 21:738-48.

4. Luna RA, Oezguen N, Balderas M, Venkatachalam A, Runge JK, Versalovic J, et al. Distinct microbiome-neuroimmune signatures correlate with functional abdominal pain in children with autism spectrum disorder. Cell Mol Gastroenterol Hepatol. 2017;3:218-30.

5. Wasilewska J, Klukowski M. Gastrointestinal symptoms and autism spectrum disorder: links and risks - a possible new overlap syndrome. Pediatr Health Med Ther. 2015;6:153-66.

6. Margolis KG, Buie TM, Turner JB, Silberman AE, Feldman JF, Murray KF, et al. Development of a brief parent-report screen for common gastrointestinal disorders in autism spectrum disorder. J Autism Dev Disord. 2019;49:349-62.

7. Bernier R, Golzio C, Xiong B, Stessman HA, Coe BP, Penn O, et al. Disruptive CHD8 mutations define a subtype of autism early in development. Cell. 2014;158:263-76.

8. Shteyer E, Edvardson S, Wynia-Smith SL, Pierri CL, Zangen T, Hashavya $\mathrm{S}$, et al. Truncating mutation in the nitric oxide synthase 1 gene is associated with infantile achalasia. Gastroenterology. 2015;148:533-6 e534.

9. Sivarao DV, Mashimo HL, Thatte HS, Goyal RK. Lower esophageal sphincter is achalasic in nNOS(-/-) and hypotensive in W/W(v) mutant mice. Gastroenterology. 2001;121:34-42.

10. Grubisic V, Kennedy AJ, Sweatt JD, Parpura V. Pitt-Hopkins mouse model has altered particular gastrointestinal transits in vivo. Autism Res. 2015;8:629-33.

11. Fröhlich H, Kollmeyer ML, Linz V, Stuhlinger M, Groneberg D, Reigl A, et al. Gastrointestinal dysfunction in autism: altered motility and achalasia in Foxp1 $1^{+-}$mice PNAS 2019; (2019 Oct 14. pii: 201911429. https://doi.org/10.1073/pnas.1911429116.

12. Margolis KG, Li Z, Stevanovic K, Saurman V, Israelyan N, Anderson GM, et al. Serotonin transporter variant drives preventable gastrointestinal abnormalities in development and function. J Clin Investig. 2016;126:2221-35.

13. Hosie S, Ellis M, Swaminathan M, Ramalhosa F, Seger GO, Balasuriya GK, et al. Gastrointestinal dysfunction in patients and mice expressing the autism-associated R451C mutation in neuroligin-3. Autism Res. 2019;12:1043-56.

14. Leembruggen AJL, Balasuriya GK, Zhang J, Schokman S, Swiderski K, Bornstein JC, et al. Colonic dilation and altered ex vivo gastrointestinal motility in the neuroligin-3 knockout mouse. Autism Res. 2020;13:691-701.

15. James DM, Kozol RA, Kajiwara Y, Wahl AL, Storrs EC, Buxbaum JD, et al. Intestinal dysmotility in a zebrafish (Danio rerio) shank3a; shank3b mutant model of autism. Mol Autism. 2019;10:3.

16. Brosens E, Burns AJ, Brooks AS, Matera I, Borrego S, Ceccherini I, et al. Genetics of enteric neuropathies. Dev Biol. 2016;417:198-208. 